\title{
Fertility Onset, Spermatogenesis, and Pubertal Development in Male Rats: Effect of Graded Underfeeding ${ }^{1}$
}

\author{
ALLAN R. GLASS, DAMON C. HERBERT, AND JEFFREY ANDERSON
}

\begin{abstract}
Departments of Medicine and Clinical Investigation, Walter Reed Army Medical Center. Washington, D.C. 20307-5001: Department of Medicine. Uniformed Services University of the Health Sciences, Bethesda, Maryland 20814-4799; and Department of Cellular and Structural Biology, University of Texas Health Science Center. San
\end{abstract} Antonio, Texas 78284

\begin{abstract}
Undernutrition has proven to be a useful model for exploring the relationship between growth and pubertal development in female rats, such as the "critical body weight" hypothesis of pubertal timing, but corresponding studies in the male have been hampered by lack of specific discrete markers of puberty similar to vaginal opening or first estrus in females. In the current study, we explored the effect of five different levels of food intake (as low as one-thrid of normal) beginning at weaning on pubertal development and timing in male rats, using the date of the initial successful conception with normal females as a discrete marker for puberty in males. In underfed males, there was a weak inverse correlation $(r=$ $-0.31, p<0.05)$ between the age at puberty and the growth rate, the latter being used as an index of the degree of underfeeding. In contrast, there was a strong direct correlation $(r=0.78, p<0.001)$ between body weight at puberty and growth rate. In the most severely underfed groups, the Lee index of body fat remained subnormal before and after puberty. Initial litter size also tended to be reduced when the males were underfed. At age 51 days (prior to puberty), graded underfeeding led to progressive reductions in serum luteinizing hormone and follicle-stimulating hormone levels as well as in parameters of androgen status (serum and testicular testosterone, prostate, and seminal vesicle weights). Testicular size was also reduced, but daily sperm production rate was not greatly affected by underfeeding. Testicular histology at age 51 days revealed mature step 19 spermatids in all groups, with some reduction in seminiferous tubular diameter in the most severely underfed group. The effect of underfeeding on testicular testosterone and spermatogenesis appeared to decrease as underfeeding was continued for an additional 70 days. We conclude that graded underfeeding beginning at weaning leads to major reductions in gonadotropins and androgens but has less effect on spermatogenesis or the timing of puberty. Therefore, in normal rats, the timing of puberty is closely related to spermatogenic development, which can proceed once initiated despite low gonadotropin and androgen levels. Underfed male rats have low body weights and low body fats at puberty, refuting the "critical body weight" and "critical body fat" hypotheses of pubertal timing. (Pediatr Res 20: 1161-1167, 1986)
\end{abstract}

Received April 11, 1986; accepted June 24, 1986.

Correspondence and reprint requests to Allan R. Glass, M.D., Endocrinoloy Service. 7D. Walter Reed Army Medical Center. Washington, DC 20307-5001.

Supported by the Department of Clinical Investigation, Walter Reed Army Medical Center.

' The opinions or assertions contained herein are the private views of the authors and are not to be construed as official or as reflecting the views of the Department of the Army or the Department of Defense.
Abbreviations

LH, luteinizing hormone

$\mathrm{FSH}$, follicle-stimulating hormone

For a number of years, researchers have proposed that the two major developmental processes of growth and sexual maturation are directly linked to each other. For example, Frisch (1) has proposed that the timing of puberty is linked to attainment of either a "critical pubertal body weight" or a "critical pubertal body fatness." Manipulation of pubertal timing by undernutrition has proven to be a useful model for exploring these hypotheses (2). For example, studies in underfed female rats have indicated that the timing of puberty, defined by vaginal opening or first estrus, does not seem to be related to attainment of either a critical pubertal body weight or critical pubertal body fat (3, 4). Similar studies of puberty in undernourished males have been hampered by the lack of a discrete marker of puberty comparable to vaginal opening or first estrus in females. Moreover, previous studies of the effect of undernutrition on sexual maturation have generally employed only a single level of nutritional alteration even though simultaneous analysis of several different levels of underfeeding might be more sensitive in detecting an effect of undernutrition on puberty than comparison of single control and experimental groups. In the current study, we have circumvented these problems by examining rats given five different levels of food intake and by using, as a marker of puberty in males, the first successful conception with normal females. The effect of such graded undernutrition on the age and body weight at puberty in male rats was correlated with the corresponding changes in androgens, gonadotropins, and spermatogenesis in order to shed light on the mechanism of pubertal disruption in undernutrition and to clarify the relative importance of these factors in normal puberty.

\section{MATERIALS AND METHODS}

Male Sprague-Dawley derived CD rats (Charles River Labs, Wilmington, MA), all born on the same day, were weaned at age 21 days and randomly assigned to one of five dietary regimens. One group was fed ad libitum, using a diet previously described (5) which contains $18 \%$ casein and $70 \%$ carbohydrate and is supplemented with vitamins and minerals to meet minimal requirements even at low food intake levels. The other four dietary groups were given the same diet but at four different levels of food intake, with food intake being adjusted throughout the experiment in order to maintain separation of the growth curves and yet permit continued growth (Fig. 1). Food intake in 


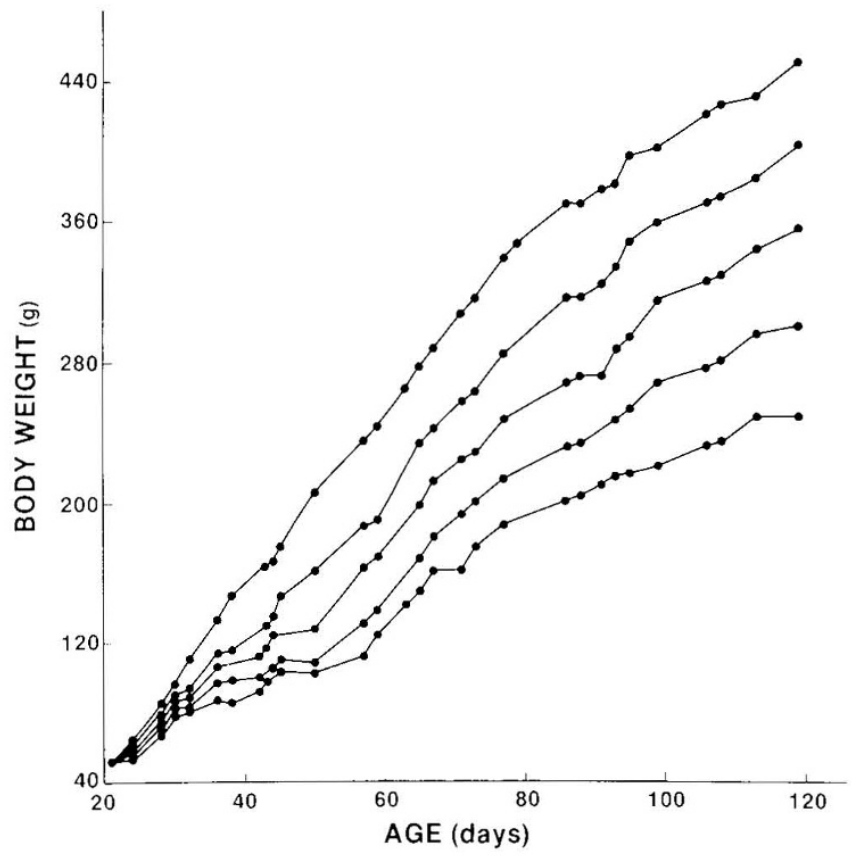

Fig. 1. Growth curves for the five dietary groups.

the fastest growing (ad libitum fed) group ranged from $7 \mathrm{~g} /$ day at the start of the experiment up to $26 \mathrm{~g}$ /day at age 121 days, while in the slowest growing group food intake started at $3 \mathrm{~g} /$ day and increased gradually to a final value of $9 \mathrm{~g} /$ day at age 121 days. The average growth rate in body weight over the course of the experiment, which was used as an index of the degree of underfeeding, ranged from 1.9 to $5.0 \mathrm{~g}$ /day in the five dietary groups. All animals were individually housed, given free access to water, and exposed to a $14 / 10$ light-dark cycle.

Beginning at age 36 days, 10 animals from each of the five dietary groups (total of 50 males) were placed each night in individual mating cages one male per cage, each of which contained two normal adult females. These mating cages were provided with water but not food. Each morning, the males were removed from the mating cages and placed in their normal individual housing cages, where they were fed according to their assigned dietary regimens. The normal females were fed a normal diet ad libitum during the day. Each male was mated with the same two females each night. Females were examined daily for parturition, and the date of conception was determined by backdating from the age of delivery. For each of the male rats, the date of conception for the first female of each pair to conceive determined the age at fertility onset (puberty), while the body weight of each male on the day of conception was determined from the growth records maintained for each individual rat. Determination of each male rat's age and body weight at conception was also made for the second female of each pair to conceive.

Eight to 10 animals from each of the five dietary groups were sacrificed at ages 51,81 , and 121 days, corresponding to 30,60 , and 100 days, respectively, on the dietary regimens. Sacrifice was performed by rapid aortic exsanguination under light ether anesthesia to maximize blood collection. Body weight, prostate weight, seminal vesicle weight (after expression), and testis weight were recorded for each animal, and nasoanal and tail lengths were measured. One testis was fixed in Bouin's solution for subsequent histologic examination under light microscopy, while the other testis was frozen for subsequent analysis. Half of this testis was used for determination of the daily sperm production rate by the method of homogenization-resistant testicular spermatids (6), while the other half testis was homogenized in phosphate buffer and assayed for testosterone content. Blood was allowed to clot at room temperature and the serum was separated and stored at $-20^{\circ} \mathrm{C}$. Serum $\mathrm{LH}$ and FSH were measured by radioimmunoassay in all serum samples using the assay kits provided by the National Pituitary Agency, NIADDKD (intraassay variation $<9 \%$ ). Because many samples had undetectable serum LH levels (below $15 \mathrm{ng} / \mathrm{ml}$ ), the serum LH results were expressed as the percentage of samples in each group which had detectable serum LH levels. Testosterone was measured in serum samples from 51-day animals and in testicular homogenates by radioimmunoassay (Coat a Count, Diagnostic Products, Los Angeles, CA) (intraassay variation $<5 \%$ ). Because of laboratory accident, serum from 81- and 121-day-old animals was not available for testosterone measurement. All samples from animals of the same age were run in the same assay. The Lee index of fatness was calculated for each animal as cube root of weight divided by length (7). Statistical analysis was done by Student's $t$ test and linear regression, with the average growth rate of each group serving as an index of the degree of underfeeding.

\section{RESULTS}

Pubertal timing. The age and weight of underfed male rats at puberty, as determined from the first successful conception with normal females, is shown in Figure 2. There is a weak, but statistically significant, inverse correlation $(r=0.31, p<0.05)$ between the age at puberty and the growth rate, the latter being used as an index of the degree of underfeeding. However, the
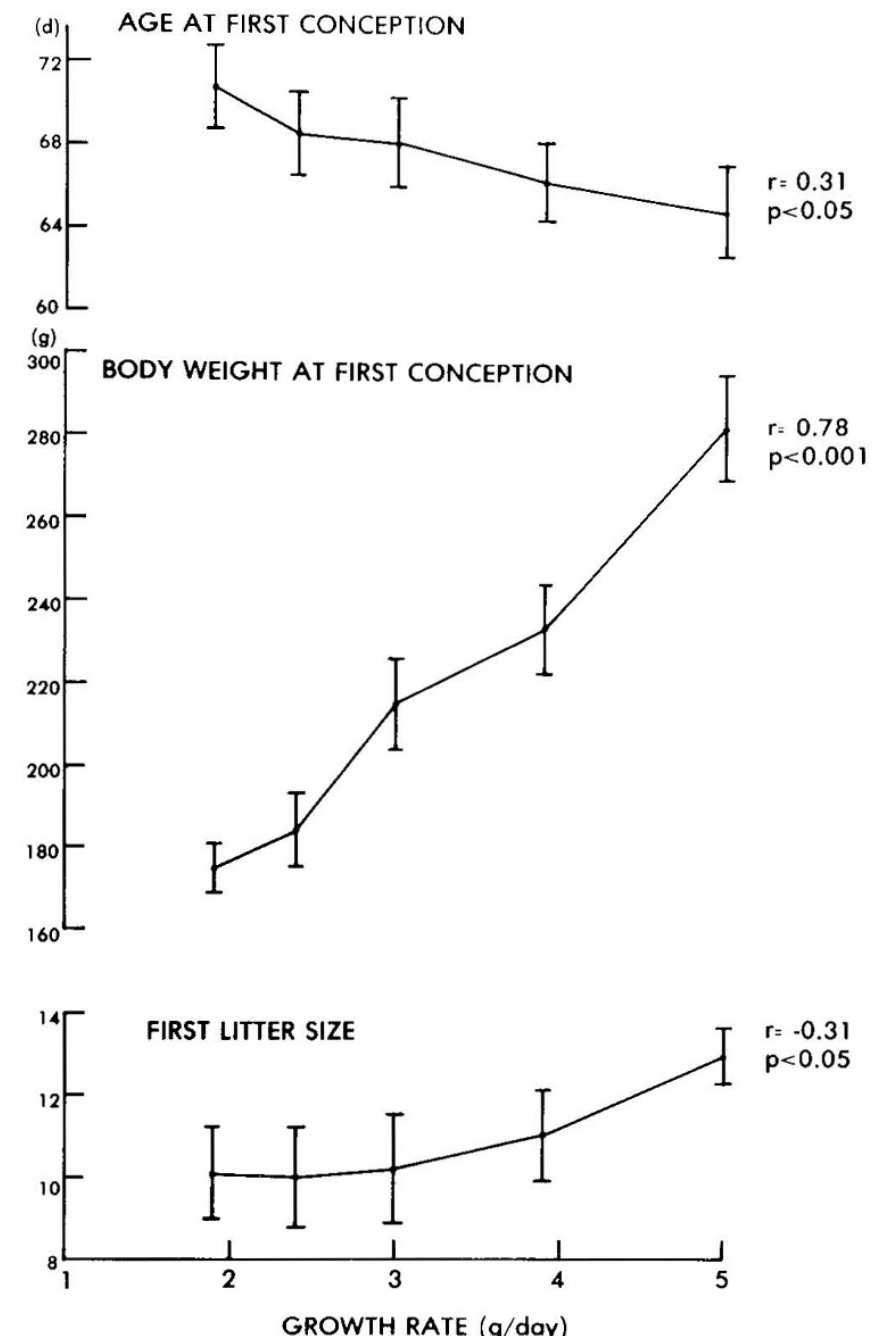

Fig. 2. Age at puberty (top), body weight at puberty (middle), and first litter size (bottom) in the five dietary groups as a function of growth rate, an index of the degree of undernutrition (mean \pm SEM; $n=8-10$ ). 
mean age at puberty did not differ significantly between the fastest and slowest growing groups. In contrast, the body weight at puberty correlated strongly with the growth rate $(r=0.78, p$ $<0.001$ ), with underfed rats attaining puberty at lower body weights than normally fed rats (Fig. 2). There was a weak, but statistically significant, correlation $(r=0.31, p<0.05)$ between initial litter size and growth rate (Fig. 2). The correlation between age at second conception and growth rate $(r=-0.43, p<0.01)$ (Fig. 3) was somewhat stronger than that between age at first conception and growth rate (Fig. 2). However, the correlations between growth rate and either body weight at second conception $(r=0.81, p<0.001)$ or the second litter size $(r=0.33, p<0.05)$ (Fig. 3) were similar to those seen for the first conception. Thus, in male rats, graded underfeeding produces a modest delay in puberty and a small reduction in litter size, but the body weight at puberty is markedly decreased as food intake is reduced.

Growth and body fatness. Graded underfeeding produced progressive reductions not only in body weight (Table 1), as intended by the experimental design, but also in linear growth, as typified by nasoanal and tail lengths $(r=0.84-0.93, p<0.001)$ (Fig. 4). The Lee index, an indicator of body fatness, increased between age 51 and 81 days in the normally fed rats (Table 1). Since virtually all animals in all groups had initial conception prior to age 81 days, while none had conception prior to 51 days of age, the latter can be considered a prepubertal age and the former a postpubertal age. The three slowest growing groups had Lee indexes before and after puberty that were significantly lower
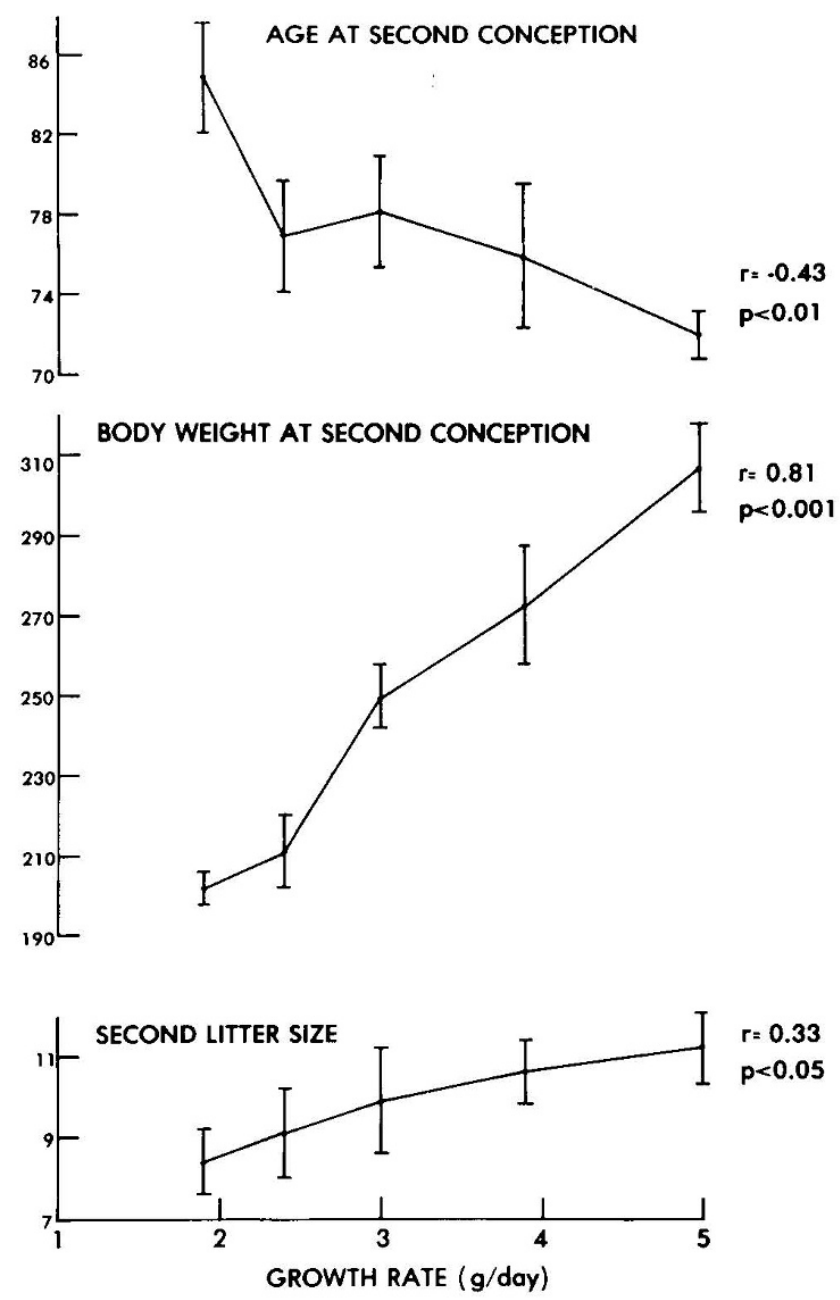

Fig. 3. Age at second conception (top), body weight at second conception (middle), and second litter size (bottom) in the five dietary groups as a function of growth rate (mean \pm SEM; $n=8-10$ ). than the Lee index, either before or after puberty, in the normally fed rats (Table 1). Thus, underfed rats went through puberty without ever having attained the level of body fatness that normally fed rats reached at puberty.

Androgens and gonadotropins. At age 51 days, graded underfeeding led to progressive reductions in prostate and seminal vesicle weights (Fig. 5), serum testosterone $(r=0.71, p<0.001)$ (Table 2), and testicular testosterone content (Fig. 6). Qualitatively similar effects of underfeeding on prostate and seminal vesicle weight were also seen at 81 and 121 days of age (Fig. 5). Testis testosterone was also reduced by undernutrition at 81 days (Fig. 7) but not at 121 days (Fig. 8). The progressive reduction in serum LH $(r=0.95, p<0.01)$ and FSH $(r=0.68, p<0.001)$ induced by underfeeding through age 51 days disappeared by age 121 days (Table 2). Thus, androgen deficiency and low gonadotropin output induced by underfeeding were apparent as early as age 51 days, with progressive adaptation by age 121 days.

Spermatogenesis. Development of spermatogenesis in underfed rats was monitored using testis weight, testis histology, and daily sperm production rate (assessed by the method of homogenization-resistant testicular spermatids). At age 51 days, graded underfeeding led to a progressive reduction in testicular size but not in daily sperm production rate (Fig. 6). Daily sperm production rate correlated significantly with testis weight $(r=$ $0.58, p<0.01$ ) but not with any of the parameters of androgenic development (serum or testis testosterone, prostate, or seminal vesicle weight). In contrast, when a similar variation in growth and development status was produced by examining normal animals studied at different ages (rather than variously underfed animals examined at the same age), the correlation between daily sperm production rate and testis weight was much higher ( $r=$ $0.97, p<0.001)$, and significant $(p<0.01)$ correlations were observed between daily sperm production rate and prostate weight $(r=0.90)$, seminal vesicle weight $(r=0.90)$, and serum testosterone $(r=0.59)$.

Mature step 19 spermatids were present at age 51 days in the testes from all five dietary groups in the current study, although seminiferous tubular diameter was somewhat smaller in the slowest growing group than in the fastest growing group (229 \pm 8 versus $256 \pm 7 \mu \mathrm{m} ; p<0.05$ ) (Fig. 9). Testes from the three groups with intermediate growth rates had intermediate, and similar, histologic appearances.

When underfeeding was prolonged to 60 days (age 81 days) undernutrition still led to a reduction in testicular size, and a weak relationship between underfeeding and daily sperm production rate per testis (but not per $\mathrm{g}$ testis weight) became apparent (Fig. 7). Weak effects of undernutrition on testicular size and daily sperm production rate per testis persisted after 100 days of underfeeding (age 121 days; Fig. 8). Testis histology showed mature sperm in all dietary groups at both age 81 and age 121 days.

\section{DISCUSSION}

In the current study, underfeeding of male rats by as much as $70 \%$ led to a minimal delay in puberty, defined for this study as onset of successful fertility. This pubertal delay was demonstrated only by examining multiple groups subject to graded underfeeding and by using regression analysis; simple two group comparisons would not have picked up the pubertal delay. Previous studies in male rats (8) and mice (9) showing that postweaning undernutrition can reduce subsequent fertility rates indirectly support this finding, although in those studies fertility onset was not determined as fixed endpoint. By contrast, postweaning undernutrition to a similar degree in female rats produces a marked delay in puberty, as defined by vaginal opening or first estrus (3). This difference between males and females is particularly striking in view of the fact that the time interval between onset of underfeeding and occurrence of pubertal markers (vaginal opening in females, fertility onset in males), and hence the 
Table 1. Body wt and fatness in underfed rats*

\begin{tabular}{|c|c|c|c|c|c|}
\hline & \multicolumn{5}{|c|}{ Growth rate (g/day) } \\
\hline & 5.0 & 3.9 & 3.0 & 2.4 & 1.9 \\
\hline \multicolumn{6}{|l|}{ Body wt (g) } \\
\hline Age 51 days & $209 \pm 6$ & $167 \pm 3$ & $131 \pm 1$ & $108 \pm 1$ & $98 \pm 3$ \\
\hline Age 81 days & $345 \pm 7$ & $296 \pm 2$ & $249 \pm 1$ & $213 \pm 2$ & $179 \pm 1$ \\
\hline Age 121 days & $447 \pm 9$ & $400 \pm 4$ & $355 \pm 3$ & $301 \pm 2$ & $252 \pm 3$ \\
\hline \multicolumn{6}{|c|}{ Lee index of fatness $\left(\times 10^{3}\right)$} \\
\hline Age 51 days & $297.6 \pm 1.8$ & $298.0 \pm 1.3$ & $291.5 \pm 1.4 \dagger$ & $287.3 \pm 2.4 \dagger$ & $281.9 \pm 2.4 \dagger$ \\
\hline Age 81 days & $305.2 \pm 2.6$ & $299.0 \pm 2.7$ & $291.6 \pm 1.9 \dagger$ & $288.3 \pm 1.3 \dagger$ & $282.5 \pm 2.5 \dagger$ \\
\hline Age 121 days & $305.3 \pm 1.9$ & $303.0 \pm 2.6$ & $297.9 \pm 2.1$ & $298.5 \pm 1.1$ & $290.1 \pm 1.5$ \\
\hline
\end{tabular}

* Mean $\pm \operatorname{SEM}(n=8-10)$.

$\dagger p<0.05$ versus growth rate of $5.0 \mathrm{~g} /$ day (age 51 or 81 days).
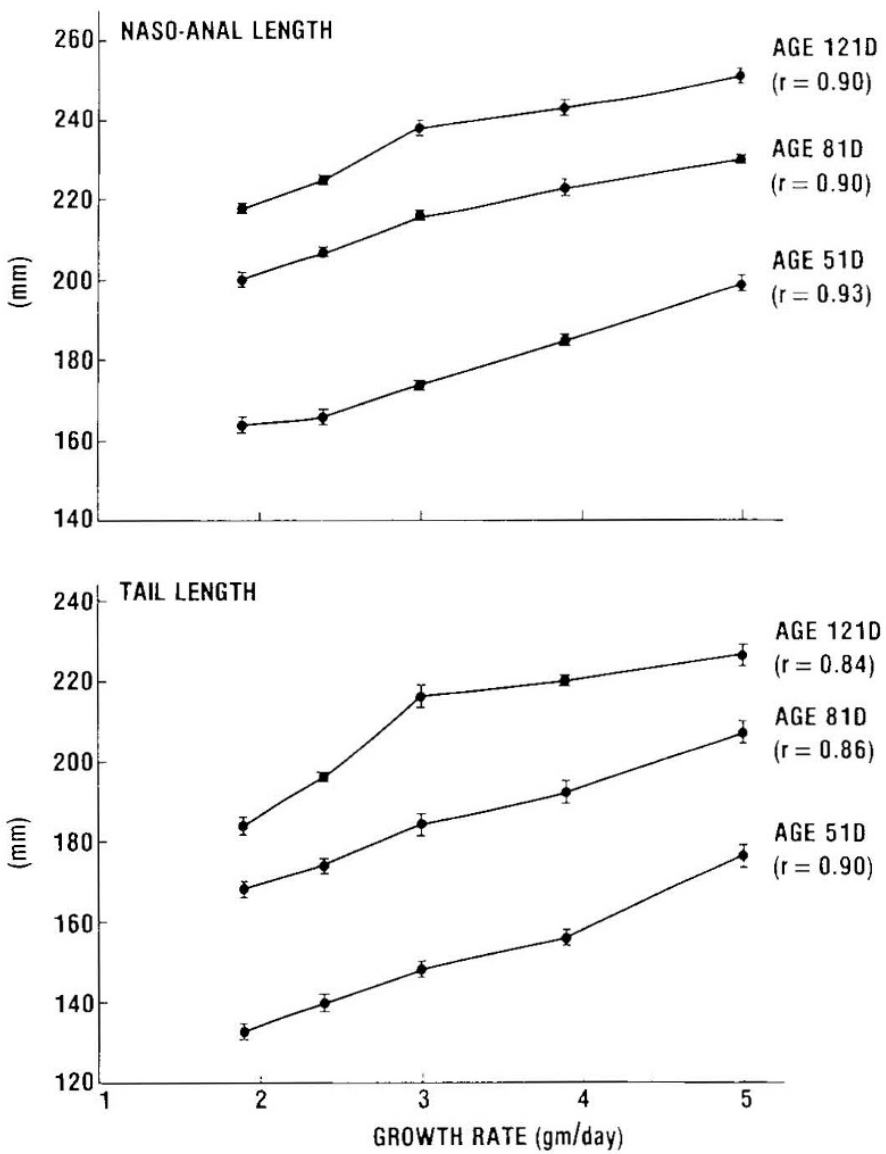

Fig. 4. Nasoanal length (top) and tail length (bottom) at three ages in the five dietary groups as a function of growth rate (mean $\pm \mathrm{SEM} ; n=$ $8-10)$.

potential time during which undernutrition could act to delay puberty, is much longer for males (6wk) than for females (2wk). This difference also emphasizes the importance, in the male, of events occurring prior to weaning (the start of underfeeding in this study), an idea supported by previous studies showing that underfeeding of male mice before weaning leads to a substantial delay in fertility onset (10).

Extensive controversy has revolved around the question of whether pubertal timing is directly linked to attainment of a particular milestone in somatic growth. Frisch (1) has proposed that puberty is triggered by attainment of a particular body weight or body fatness, but our previous studies have not substantiated this theory in underfed female rats $(3,4)$. In the current study, the body weight at puberty is underfed male rats declined pro-
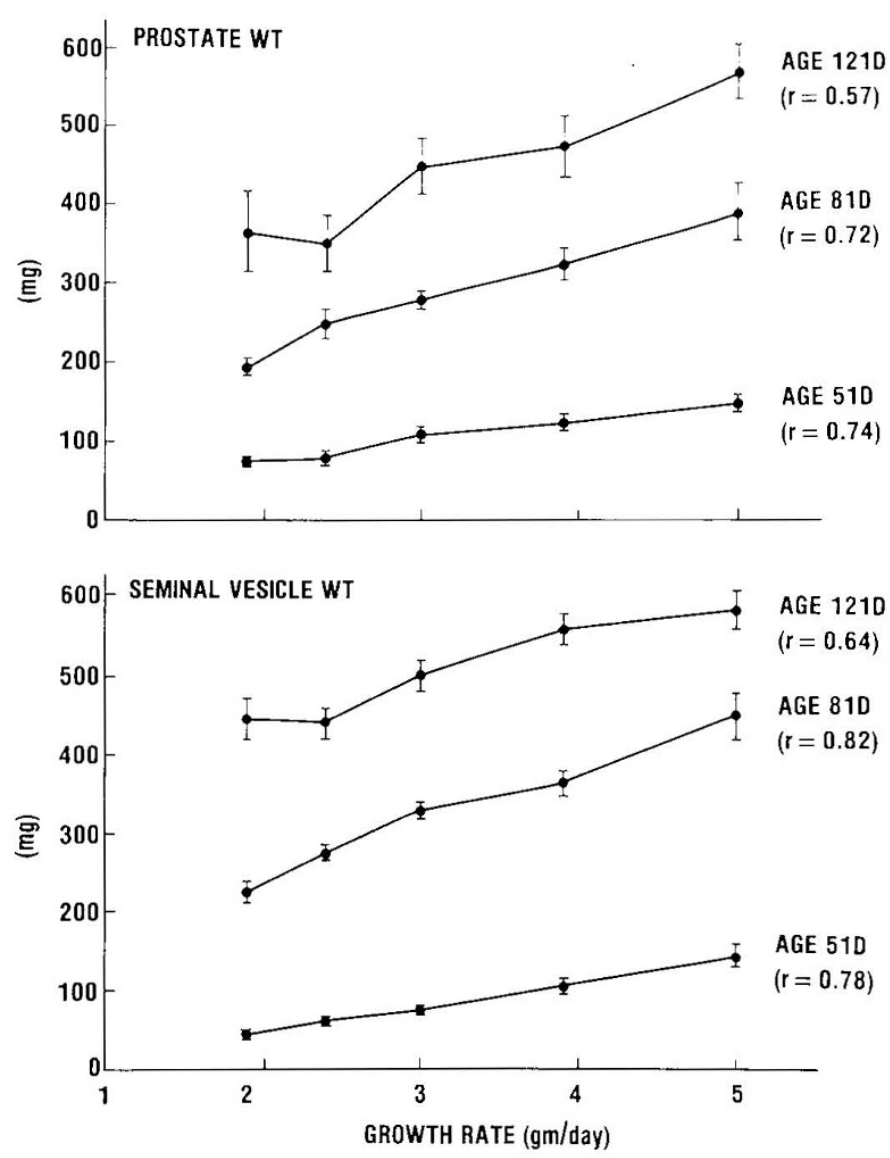

Fig. 5. Prostate weight (top) and seminal vesicle weight (bottom) at three ages in the five dietary groups as a function of growth rate (mean \pm SEM; $n=8-10$ ).

gressively as the degree of underfeeding increased. Similarly, male mice underfed before weaning attain fertility at lower body weights than normal animals (10). Of interest is the difference between males and females in the pattern of how pubertal body weight varies as a function of increasing undernutrition, with males showing a linear decline in pubertal body weight as undernutrition increases (current study) and females showing a parabolic relationship between pubertal body weight and degree of undernutrition (3). In addition, the percent body fat, estimated by the Lee index, remained low before and after puberty in the underfed males in the present study. Thus, for neither male nor female rats can the "critical body weight" or "critical body fat" hypotheses of pubertal timing be substantiated.

Successful fertility, whose onset was used as a pubertal marker 
Table 2. Serum hormone concentrations in underfed rats*

\begin{tabular}{|c|c|c|c|c|c|}
\hline & \multicolumn{5}{|c|}{ Growth rate (g/day) } \\
\hline & 5.0 & 3.9 & 3.0 & 2.4 & 1.9 \\
\hline \multicolumn{6}{|c|}{ Serum LH $(\%$ detectable $) \dagger$} \\
\hline Age 51 days & 100 & 40 & 10 & 0 & 0 \\
\hline Age 81 days & 100 & 30 & 40 & 10 & 0 \\
\hline Age 121 days & 70 & 70 & 90 & 70 & 44 \\
\hline \multicolumn{6}{|c|}{ Serum FSH (ng/ml) } \\
\hline Age 51 days & $511 \pm 26$ & $433 \pm 30$ & $367 \pm 25$ & $313 \pm 13$ & $341 \pm 23$ \\
\hline Age 81 days & $332 \pm 51$ & $331 \pm 25$ & $278 \pm 17$ & $323 \pm 18$ & $256 \pm 13$ \\
\hline Age 121 days & $287 \pm 20$ & $381 \pm 35$ & $254 \pm 17$ & $289 \pm 27$ & $269 \pm 28$ \\
\hline \multicolumn{6}{|c|}{ Serum testosterone $(\mathrm{ng} / \mathrm{dl})$} \\
\hline Age 51 days & $213 \pm 33$ & $112 \pm 15$ & $67 \pm 13$ & $72 \pm 11$ & $40 \pm 7$ \\
\hline
\end{tabular}

* Mean \pm SEM (except serum LH); $n=8-10$ per group.

$\dagger$ Greater than $15 \mathrm{ng} / \mathrm{ml}$.
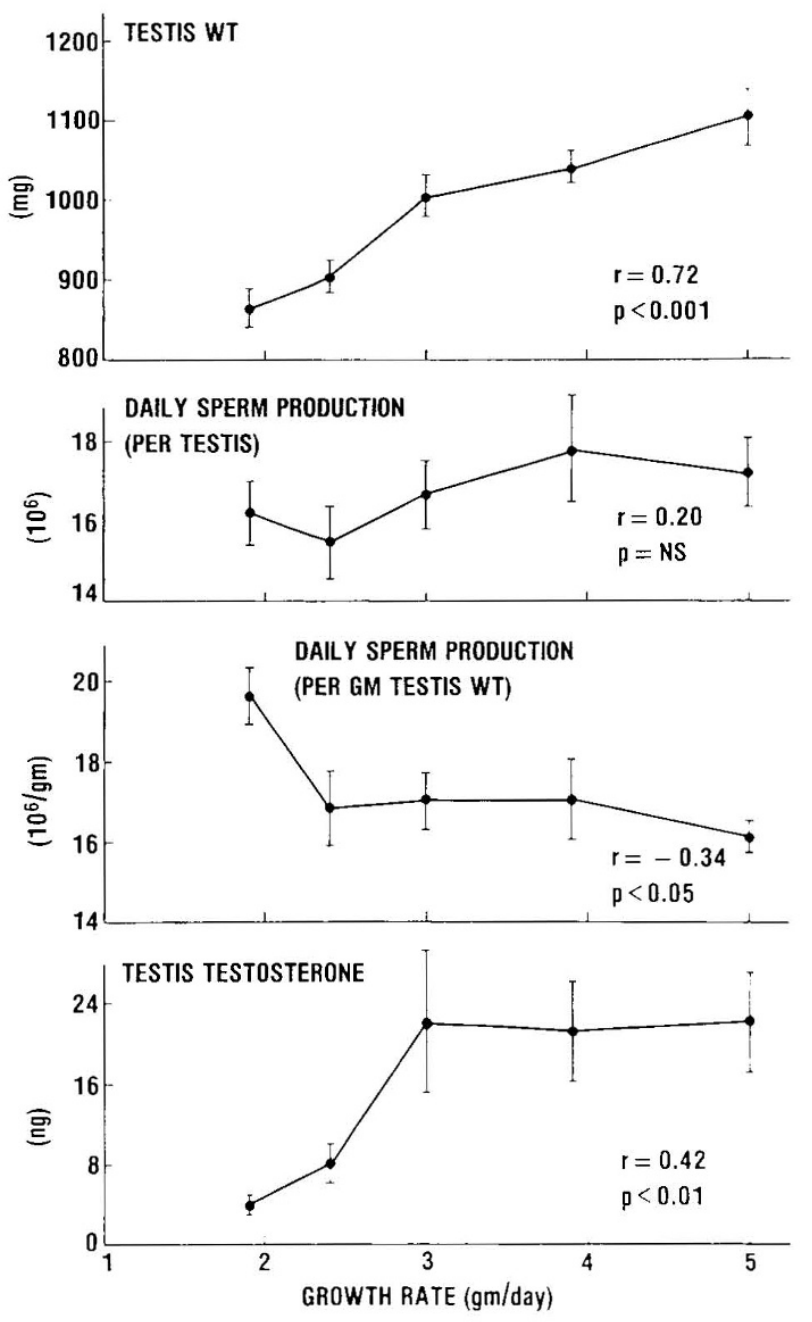

Fig. 6. Testis weight (top), daily sperm production rate (middle), and testicular testosterone content (bottom) at age 51 days (30 days of underfeeding) in the five dietary groups as a function of growth rate (mean $\pm \mathrm{SEM} ; n=8-10$ ).

in the current study, requires adequate development of androgenic, spermatogenic, and behavioral components. These factors are interdependent, particularly since both spermatogenesis and sexual behavior are androgen dependent. In the current study, underfeeding of male rats led to reduction in androgen production, as assessed by serum and testis testosterone and sexual
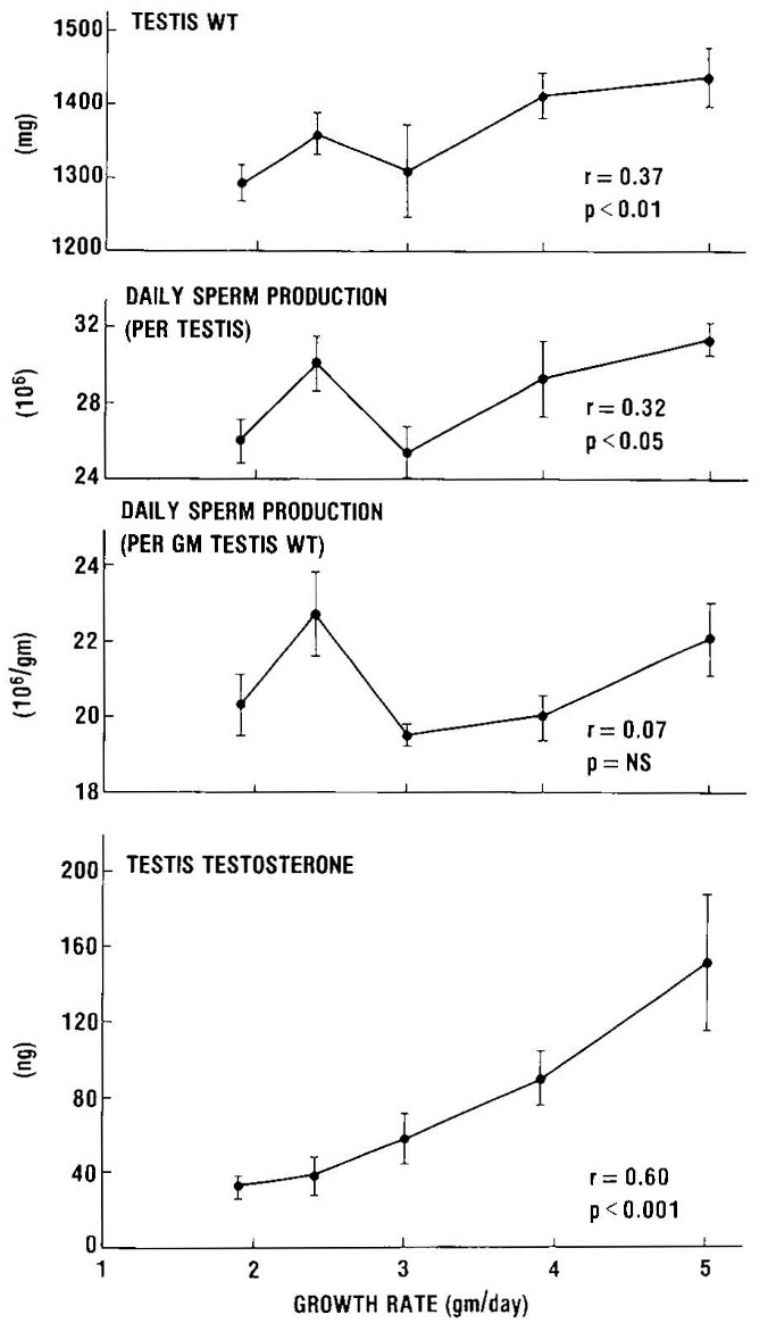

Fig. 7. Testis weight (top), daily sperm production rate (middle), and testicular testosterone content (bottom) at age 81 days (60 days of underfeeding) in the five dietary groups as a function of growth rate (mean $\pm \mathrm{SEM} ; n=8-10$ ).

accessory weights, as well as reduced gonadotropins. Such hypogonadotropin hypogonadism has been previously noted in undernourished rats both by us (5) and others (8). Balanopreputial separation, which reflects androgenic development, is also delayed by altered nutrition (11). Despite marked androgen deficiency, however, puberty in underfed male rats was only 

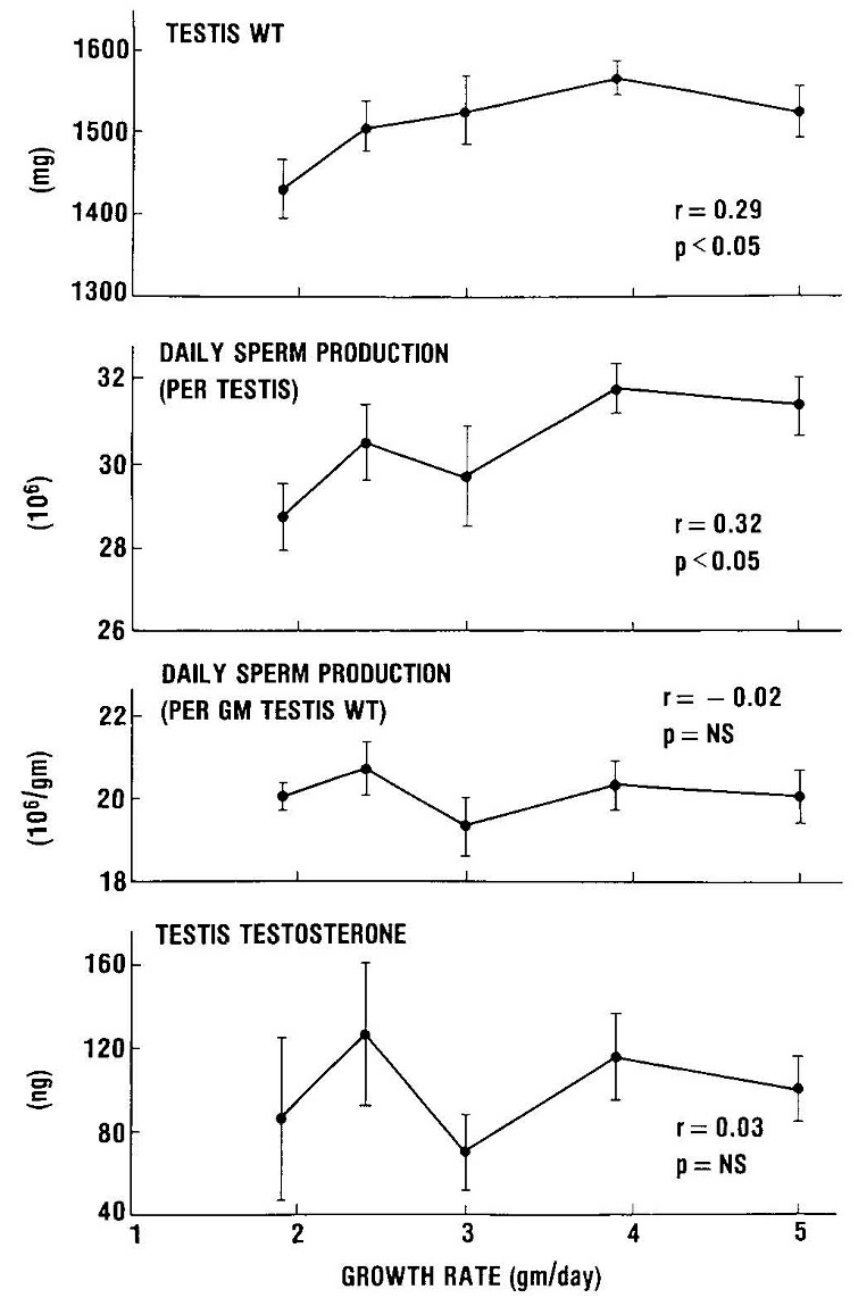

Fig. 8. Testis weight (top), daily sperm production rate (middle), and testicular testosterone content (bottom) at age 121 days (100 days of underfeeding) in the five dietary groups as a function of growth rate (mean $\pm \mathrm{SEM} ; n=8-10$ ).

slightly delayed. Similarly, in male mice underfed prior to weaning, the serum testosterone level at the time of fertility onset is lower than normal (10). These findings imply that the minimal amount of androgens required for puberty in underfed animals is less than that actually present at puberty in normally fed males and indicate that androgen production may not be the timelimiting factor in normal puberty onset.

Undernutrition affords a useful model for examining the relationship between androgen deficiency and the development of spermatogenesis. The development of spermatogenesis is thought to be closely related to intratesticular testosterone levels (12). In the current study, however, daily sperm production at age 51 days was not affected by underfeeding despite marked reductions, particularly at the lowest growth rates, in intratesticular testosterone. Several factors must be considered with regard to this discrepancy. First, other measures of spermatogenic function, such as testis size and histology, did suggest an effect of underfeeding at age 51 days. The reduced litter size observed in our study may also be a subtle reflection of impaired spermatogenesis. However, testicular size did not appear to be as good a reflection of spermatogenesis in underfed rats as it is in normally fed rats. Second, it is well recognized that substantial development of spermatogenesis takes place before weaning (13), the time when undernutrition was instituted in this study. Consequently, lower levels of intratesticular testosterone may serve to maintain spermatogenesis after weaning provided that preweaning development was unaffected. Supporting this idea is the
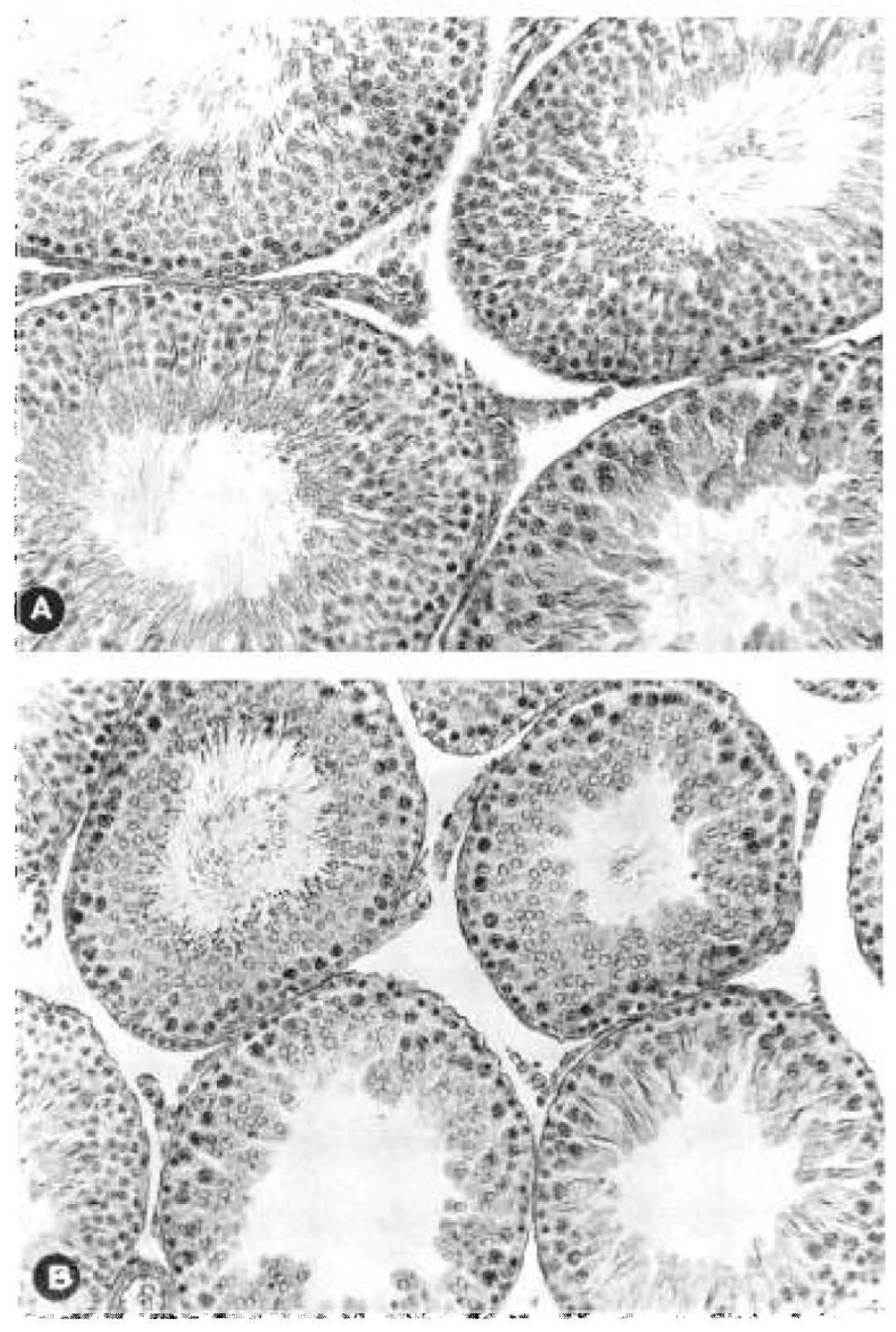

Fig. 9. Testicular histology at age 51 days in a normally fed control $(A)$ and in one animal from the most severely underfed group $(B)$. Mature step 19 spermatids are present in both animals, but seminiferous tubular diameter is smaller in the underfed rat, $\times 365$.

finding that, in mice, underfeeding limited to the preweaning period results in reduction in testicular size, testicular testosterone content, and seminiferous tubule diameter, as well as impaired histologic development of the testis $(10,14)$. By contrast, undernutrition begun as an adult seems to have little effect on spermatogenesis in rats (15) or house mice (16). Underfeeding begun before weaning and continued after weaning delays the appearance of penile sperm in rats (17), but underfeeding of guinea pigs beginning at weaning does not delay appearance of epididymal sperm despite reduction in serum testosterone and histologic evidence of altered spermatogenesis (18). In mice and rats, growth arrest induced by underfeeding after weaning produces a greater impairment of seminal vesicle development than of testis development or spermatogenesis (19). Finally, one must consider that the duration of underfeeding from weaning to puberty is relatively short in relation to the sperm cycle of the rat (about 13 days) (20). Therefore, more prolonged underfeeding might result in impairment of spermatogenesis. Our data support this concept since the effect of underfeeding on testis testosterone and daily sperm production was greater at age 81 days (after 60 days of underfeeding) than at age 51 days. Moreover, the effect of underfeeding on the timing of conception was greater when the second conception for each female pair was examined as opposed to the first conception. Despite severe underfeeding, daily sperm production rate increased over time even in the most 
severely restricted animals, and by age 121 days there was no effect of underfeeding on testis testosterone and only a borderline effect on testis size or daily sperm production rate. Thus, our data suggest that postweaning undernutrition produces a gradual effect on spermatogenesis which is minimally evident at the time of puberty, is more apparent in the early postpubertal period, and then wanes as full adult growth is ultimately attained.

Since both pubertal timing and peripubertal spermatogenesis seem to be only slightly affected by underfeeding, it is tempting to theorize that development of spermatogenesis is, in fact, the time-limiting factor for fertility onset. However, this conclusion ignores the potentially important role of the behavioral component of sexual maturation. When underfeeding includes the preweaning period, delayed onset of mounting and ejaculatory behavior have been seen $(17,21)$, although when underfeeding is limited to the postweaning period, the effect on sexual behavior is less clear-cut $(22,23)$. In one study of combined pre- and postweaning underfeeding (17), the onset of mounting behavior was delayed well beyond the first appearance of penile sperm, indicating that under these circumstances, sexual behavior may be more critical for pubertal timing than spermatogenesis. Since we did not assess sexual behavior in our study, we cannot exclude the possibility that behavioral changes are responsible for the alterations in pubertal timing we observed.

In summary, underfeeding of male rats beginning at puberty leads to a minimal delay in fertility onset but a major reduction in the body weight at fertility onset, and body fatness can remain low before and after puberty. Thus, the "critical body weight" and "critical body fatness" hypotheses of pubertal timing cannot be supported in male rats. Underfeeding seems to produce prompt and significant reductions in gonadotropin and androgen production, although spermatogenesis, as assessed by testis histology, daily sperm production rate, and litter size, is minimally affected at first. From a theoretical point of view, shutting off of reproductive function during times of food scarcity may be desirable for the survival of a species. However, since sperm development requires a fairly long time in the rat (about 52 days) relative to the animal's breeding life span, it would seem more appropriate that underfeeding should stop reproduction by suppressing androgens or sexual behavior, rather than spermatogenesis, since the former could be restarted faster than the latter after food supplies resumed. One must be very cautious about extrapolating these results to humans, however. For one thing, these studies suggest the important role of the preweaning period in sexual maturation in male animals, and the exact correlation between this period in rats and either the infantile or perinatal periods in humans is uncertain. Moreover, even strain differences, much less species differences, can alter the findings. For example, deer mice are very sensitive to the effect of undernutrition on pituitary-testicular function, while house mice are almost completely resistant (16). To the extent that the animal findings are pertinent to humans, they suggest the critical importance of the earliest stages of testicular and reproductive development, and that insults during this period are particularly noxious. On the other hand, undernutrition later in youth, after basic sper- matogenesis has been established, may be consistent with ultimately normal sexual development.

Acknowledgment. The authors thank Mrs. Estelle Coleman for expert editorial assistance.

\section{REFERENCES}

1. Frisch RE 1980 Pubertal adipose tissue: is it necessary for normal sexual maturation? Evidence from the rat and human female. Fed Proc 39:23952400

2. Glass AR, Swerdloff RS 1980 Nutritional influences on sexual maturation in the rat. Fed Proc 39:2360-2364

3. Glass AR, Harrison R, Swerdloff RS 1976 Effect of undernutrition and amino acid deficiency on the timing of puberty in rats. Pediatr Res 10:951-955

4. Glass AR, Dahms WT, Swerdloff RS 1979 Body fat at puberty in rats: alteration by changes in diet. Pediatr Res 13:7-9

5. Glass AR, Mellitt R, Vigersky RA, Swerdloff RS 1979 Hypoandrogenism and abnormal regulation of gonadotropin secretion in rats fed a low protein diet. Endocrinology 104:438-442

6. Robb GW, Amann RP, Killian GJ 1978 Daily sperm production and epididymal sperm reserves of pubertal and adult rats. J Reprod Fertil 54:103-107

7. Bernardis LL, Patterson BD 1968 Correlation between Lee index and carcas fat content in weanling and adult female rats with hypothalamic lesions. J Endocrinol 40:527-528

8. Merry BJ, Holehan AM 1981 Serum profiles of LH, FSH, testosterone, and 5 $\alpha$-DHT from 21 to 1000 days of age in ad libitum fed and dietary restricted rats. Exp Gerontol 16:431-444

9. Lee YCP, King JT, Visscher MB 1951 Calorie intake and fertility in $\mathrm{C} 3 \mathrm{H}$ male mice. Am J Physiol 167:375-378

10. Jean-Faucher C, Berger M, deTurckheim M, Veyssiere G, Jean C 1982 The effect of preweaning undernutrition upon the sexual development of male mice. Biol Neonate 41:45-51

11. Ramaley JA 1981 Puberty onset in males and females fed a high fat diet. Proc Soc Exp Biol Med 166:294-296

12. diZerega GS, Sherins RJ 1981 Endocrine control of adult testicular function. In: Burger H, deKretser D (eds) The Testis. Raven Press, New York, pp $127-140$

13. Steinberger E 1974 Maturation of male germinal epithelium. In: Grumbach MM, Grave GD, Mayer FE (eds) The Control of the Onset of Puberty. John Wiley, New York, pp 386-402

14. Jean-Faucher C, Berger M, de Turckheim M, Veyssiere G, Jean C 1982 Effect of preweaning undernutrition on testicular development in male mice. Int $\mathrm{J}$ Androl 5:627-635

15. Grewal T, Mickelsen O, Hafs HD 1971 Androgen secretion and spermatogenesis in rats following semistarvation. Proc Soc Exp Biol Med 138:723-727

16. Blank JL, Desjardins C 1985 Differential effects of food restriction on pituitarytesticular function in mice. Am J Physiol 248:R181-189

17. Larsson K, Carlsson SG, Sourander P, Forsstrom B, Hansen S, Henriksson B, Lindquist A 1974 Delayed onset of sexual activity of male rats subjected to pre- and postnatal undernutrition. Physiol Behav 13:307-311

18. Slob AK, Vreeburg JTM, ten Bosch JJVDW 1979 Body growth, puberty, and undernutrition in the male guinea-pig. Br J Nutr 41:231-237

19. Hamilton GD, Bronson FH 1986 Food restriction and reproductive development: male and female mice and male rats. Am J Physiol 250:R370-376

20. Steinberger E, Steinberger A 1976 Spermatogenic function of the testis. In: Hamilton DW, Greep RO (eds), Handbook of Physiology, Section 7: Endocrinology, Vol V: Male Reproductive System. American Physiological Society, Washington, D.C., pp 1-19

21. Forsberg G, Abrahamsson K, Sodersten P, Eneroth P 1985 Effects of restricted maternal contact in neonatal rats on sexual behaviour in the adult. $J$ Endocrinol 104:427-431

22. Ghafoorunissa 1980 Undernutrition and fertility of male rats. J Reprod Fertil 59:317-320

23. Hamilton GD, Bronson FH 1985 Food restriction and reproductive development in wild house mice. Biol Reprod 32:773-778 